threshold probability of $20 \%$ to predict cardiovascular diseases in a population based cohort of 6224 Iranians aged 30-74 years with 10year follow-up.

Results dividing NB by incidence resulted $17 \%$ and PAF shows $43 \%$ decrease in incidence, but NBF shows just $8 \%$ advantage for treatment according to the model.

Conclusion NBF seems to be a challengeable issue in policy making using risk functions.

\section{P1-190 SOCIAL DETERMINANTS OF CARDIAC DISEASE BIOMARKERS: INVESTIGATING A SWEDISH MALE COHORT AT AGES 50 AND 70}

doi:10.1136/jech.2011.142976d.83

A Khanolkar, * D Vågerö, I Koupil. Centre for Health Equity Studies, Karolinska Institutet/ Stockholm University, Stockholm, Sweden

Background Social status is associated with cardiovascular disease (CVD) prevalence and incidence. We aimed to study relationships between i) socioeconomic position (SEP) and common CVD biomarkers; cholesterol, LDL/HDL, ApoB/ApoA1 and adiponectin ii) SEP and CVD mortality in a Swedish-population-based sample, and to assess if these associations changed with age.

Design A longitudinal cohort study of men born 1920-24 with clinical measurements, blood samples, questionnaire data and register-based information on SEP and cause of death.

Methods Of 2322 men that participated in an investigation at age 50, 1221 attended a reinvestigation at age 70. SEP was measured as occupational class and educational level. Linear regression (adjusted for age, body mass index and physical activity) was used to study associations between SEP and CVD biomarkers. CVD mortality over 36 year's follow-up was analysed by Cox regression.

Results At age 50: We found significant inverse associations of education and occupational group with mean cholesterol levels, whereas LDL/HDL ratio was associated with education only. These were statistically significant after adjustment for covariates. No significant associations were found between either measure of SEP and $\mathrm{ApoB} / \mathrm{ApoA} 1$ ratio. At age 70: No significant associations were found between either measurement of SEP and any biomarker studied. Men classified as highest educated and non-manual had decreased risk for CVD mortality during follow-up.

Conclusions Associations of SEP with cholesterol levels and LDL/ $\mathrm{HDL}$ ratio that exist at age 50, are no longer found in the same group of men at age 70 . We found no significant association between SEP and adiponectin levels at age 70 .

\section{P1-191 DO USA STATE-LEVEL SOCIAL SPENDING AND INCOME INEOUALITY PREDICT INDIVIDUAL MORTALITY? A FIXED EFFECTS, INSTRUMENTAL VARIABLE ANALYSIS}

doi:10.1136/jech.2011.142976d.84

${ }^{1,2}$ D Kim. ${ }^{*}{ }^{1}$ RAND Corporation, Santa Monica, California, USA; ${ }^{2}$ Harvard School of Public Health, Boston, Massachusetts, USA

Introduction Government spending on public goods (eg, education) and social assistance (eg, cash transfers) provides plausible investments in the social determinants of health. Among rich nations, countries with higher social spending and lower income inequality show longer life expectancies. However, studies of both factors have been limited by bias from residual confounding and reverse causation. Methods This study examined data from the National Longitudinal Mortality Study on 431637 adults aged 30-74 in 48 USA states followed for 11 years. State per capita social spending (total, welfare, education, health) and income inequality (Gini coefficient) were explored as predictors of individual mortality (all-cause, cardiovascular, cancer) using linear probability models. To reduce bias, models incorporated state and time fixed effects and instrumental variables, and controlled for state- and individual-level covariates.

Results Total public spending and spending on welfare and education, but not healthcare, predicted lower probabilities of death from coronary heart disease (CHD) (per $\$ 250$ per capita spent on welfare: $\beta=-0.016, p=0.03$ ) and all causes combined (per $\$ 250$ per capita spent on welfare: $\beta=-0.031, p=0.03$ ). There were weaker associations for colon cancer and no associations for stroke. A higher Gini coefficient predicted a higher probability of CHD mortality but not all-cause mortality. Stratified models suggested stronger effects among those aged 45-59 and with incomes $<\$ 25000 /$ year.

Conclusion Higher state social spending outside the healthcare sector may reduce one's chances of dying from heart disease and all causes combined, particularly for low-income, middle-aged adults. Policies promoting economic equality may further lessen $\mathrm{CHD}$ disparities.

\section{P1-192 A SMALL AREA ANALYSIS OF INJURIES AND RELATED FACTORS: 2009 COMMUNITY HEALTH SURVEY, KOREA}

doi:10.1136/jech.2011.142976d.85

${ }^{1} \mathrm{Y} \mathrm{M}$ Kim, ${ }^{*}{ }^{2} \mathrm{H}$ Hong, ${ }^{2} \mathrm{~J} \mathrm{H} \mathrm{Lim},{ }^{3} \mathrm{~K}$ Cheong, ${ }^{3} \mathrm{~T} \mathrm{H}$ Yoon. ${ }^{1}$ Department of Preventive Medicine, Dong-A University College of Medicine, Busan, Republic of Korea; ${ }^{2}$ School of Public Health, Seoul National University, Seoul, Republic of Korea; ${ }^{3}$ Department of Preventive Medicine, Pusan National University, Busan, Republic of Korea

Introduction As the incidence and death rate of injury are relatively high in Korea, the public health concerns are now increasing. The aim of this study are (1) to describe the regional distribution and pattern of the injury prevalence, (2) to evaluate the relationship between the Korea poverty index and the regional variation of the injury.

Methods <2009 Korea Community Health Survey> was the national interview survey in Korea. The type of injury was categorised by ICECI and the age adjusted injury prevalence was calculated. The regional variation was evaluated by the index; EO (Extremal Quotient), CV (Coefficient of Variation), CVA (CV from ANOVA). For explaining the effect of Korea poverty index to regional variation, general linear model was applied.

Results The 1-year experience of all kinds of injury was more prevalent to men than to women. Falls $(30 \%)$ was most frequent type of injury. The significant regional variation was found according to the category of injury. In the urban area, the 1-year experience rate of all kinds of injury was 5.47 (4.39-6.54) in poorest region by Korea poverty index, and 4.61 (4.28-4.94) in richest region. The statistically significant linear trend was found across the quartile of poverty index ( $p$ for trend $=0.04$ ).

Discussion There were significant regional variations according the rurality, administrative regions, and the Korea poverty index. For the tackling the high prevalence and regional discrepancy of the injury, community specialised and area based intervention were needed.

\section{P1-193 TWO-YEARS MORTALITY AFTER EVIDENCE BASED DRUG THERAPY OF ACUTE MYOCARDIAL INFARCTION: A POPULATION-BASED COHORT STUDY IN ROME, ITALY}

doi:10.1136/jech.2011.142976d.86

U Kirchmayer, ${ }^{*}$ V Belleudi, N Agabiti, M D Martino, L Bauleo, L Pinnarelli, D Fusco, M Arcà, M Davoli. Department of Epidemiology of the Regional Health Service, Lazio Region, Italy

Introduction Clinical guidelines recommend treatment with evidence-based (EB) drug therapy (antiplatelets, $\beta$-blockers, agents acting on the renin-angiotensin system, statins) for patients with acute myocardial infarction (AMI). Results on long term outcomes from observational population studies are scarce.

Objectives Analysing the association between EB drug therapy and 2 years mortality in AMI patients. 